\title{
Influence of the Techniques and Degrees of Ripeness on the Nutritional Qualities and Carotenoid Profiles of Tomatoes (Solanum lycopersicum).
}

\author{
Asiata Omotayo Ibrahim, Misbaudeen Abdul-Hammed*, Samuel Adewale Adegboyega, Monsurat \\ Olajide and Akeem Abefe Aliyu
}

Department of Pure and Applied Chemistry, Ladoke Akintola University of Technology, Ogbomoso, Nigeria.

Received 24 ${ }^{\text {th }}$ Feb. 2019, Accepted 22 ${ }^{\text {nd }}$ May, 2019

DOI: 10.2478/ast-2019-0006

*Corresponding author

Misbaudeen Abdul-Hammed E-mail: mabdul-hammed@lautech.edu.ng

Tel: +2348069151819

\begin{abstract}
Tomato is a significant vegetable crop with numerous health benefits derived from its carotenoids, flavonoids and other phytonutrients contents. This work studies the nutritional qualities and carotenoids contents of five different cultivars of tomatoes (San Marz, Nasmata, Roma VF, Ogbomoso local and 4-lobes). The variations of $\mathrm{pH}$, titratable acidity, reducing sugar, total solid, lycopene and beta-carotene contents of these tomatoes were investigated under ambient temperature and field ripening techniques and the mean values of these parameters investigated at different ripening stages and techniques were compared. Lycopene contents were significantly higher $(\mathrm{p}<0.05)$ in tomatoes subjected to field ripening compared with those ripened under ambient temperature. The highest lycopene content $(17.18 \mu \mathrm{g} / \mathrm{g})$ was observed in Roma VF cultivar at fully-ripe stage under field ripening technique while the lowest value $(0.64 \mu \mathrm{g} / \mathrm{g})$ was in 4-lobes cultivar at semi-ripe stage under ambient temperature ripening. Similar trend was observed in the variation of betacarotene (a pro-Vitamin A index) among the tomato cultivars. The evaluated reducing sugar contents (ranging from 1.84 to $5.23 \mu \mathrm{g} / \mathrm{g}$ ) were significantly higher $(\mathrm{p}<0.05)$ in fully-ripe tomatoes compared to semi-ripe ones under field ripening and the trend was reversed for some cultivars under ambient temperature ripening. The titratable acidities of the tomatoes were significantly higher at the semi-ripe stage $(0.24$ to $0.38 \%)$ under field ripening than those obtained under ambient temperature ripening ( 0.15 to $0.25 \%$ ). The $\mathrm{pH}$ of the tomatoes ranged from 3.58 to 4.07 and 3.46 to 5.40 under field and ambient temperature ripening, respectively, and the higher $\mathrm{pH}$ values obtained under ambient temperature ripening condition could make such tomatoes unsuitable in tomato processing plants. Consumption of tomatoes for the purpose of dietary antioxidant lycopene and pro-Vitamin A could maximally be achieved at fully-ripe stage under field ripening condition.
\end{abstract}

Keywords: Tomato ripening; Postharvest; Lycopene; Beta-carotene; Antioxidant; Nutrition. 


\subsection{Introduction}

Tomato (Solanum lycopersicum) is a standout among the most significant World vegetables that are regularly consumed (Shankara et al., 2005). It contains several phytochemicals such as carotenoids (lycopene and betacarotene), phenolic compounds, ascorbic acid (Raiola et al., 2014), flavonoids and phenolic acids, especially chlorogenic acids (Slimestad and Verheul, 2009). The antioxidant constituents of tomatoes such as lycopene and beta-carotene could help in fighting against free radicals in human body and this has made tomatoes the fruit of interest to many researchers (Ansari and Gupta, 2004). Other health benefits of tomatoes include good eye sight, good gut health, protection against cardiovascular diseases, prevention against skin problem and urinary tract infection, among others (Stahl and Sies, 2003). Tomato products like ketchup, paste and juices are also rich lycopene sources (Burton-Freeman and Reimer, 2011). The antioxidant activities of lycopene could be linked to its singlet oxygen quenching ability and to scavenge peroxyl radical, which makes it to be effective against cancer incidences (Devasagayam et al., 1992). The presence of lycopene in human blood at a high concentration helps in fighting mutagens, which cause cancer as a result of DNA damages, and this powerful phytonutrient act as a strong antioxidant in a natural defense pathway. On the other hand, beta-carotene is a pro-vitamin A, which has been identified as important photochemical useful in the prevention of coronary diseases and cancer (Stahl and Sies, 2003). The concentrations of lycopene and beta-carotene vary considerably among species, lineage or cultivars. Besides vitamin A, tomato also contains other vitamins such as thiamine (B1), riboflavin (B2), pantothenic acid (B3), niacin, folic acid, biotin, ascorbic acid (C) and $\alpha$-tocopherol (E). Furthermore, numerous studies have reported the significance of ascorbic acid to human health due to its strong antioxidant activity (Abdulnabi et al., 1997).

The nutritional qualities and antioxidant components in fruits and vegetable crops are influenced by various pre-harvest and post-harvest factors (Opara and Al-Ani, 2010; Fawole et al., 2012; Kahlaoui et al., 2018;). Other factors such as tomato variety, techniques of cultivation, locality and the period of sampling may influence the nutritional composition of tomatoes (Suárez et al., 2008).

Therefore, this work aims to examine the effect of ripening techniques and the degree of ripeness on the variations in total solids, $\mathrm{pH}$, titratable acidity, reducing sugar and carotenoids (like lycopene and beta-carotene) contents of five tomato cultivars, that are commonly grown in Nigeria.

\subsection{Materials and Method}

\section{Sample preparation}

The seeds of San Marz, Roma VF, Ogbomoso-local tomato cultivars were obtained locally from a farm settlement at Onipaanu Village area located in Surulere Local Government Area of Oyo State, Nigeria while Nasmata and 4-lobes cultivars were collected at the International Institute of Tropical Agriculture (IITA), Ibadan, Oyo State, Nigeria. The five tomato cultivars were planted in an organic farmland (in the absence of fertilizer) at Kuye Area, Ogbomoso, Nigeria (Latitude $8^{\circ} 8^{\prime} 0^{\prime \prime} \mathrm{N}$, Longitude $4^{\circ} 16^{\prime} 0^{\prime \prime} \mathrm{E}$ ) between June and September, 2015. Identification of the tomatoes was carried out at the LAUTECH Herbarium, Ogbomoso, Nigeria, with deposited voucher numbers LHO521, LHO522, LHO523, LHO524 and
LHO525, for San Marz, Roma VF, Ogbomoso-local, Nasmata, and 4-lobes, respectively. Random selection of the tomatoes was made with respect to the cultivars and ripening stages and the harvested tomatoes were collected into a non-transparent polythene bags in order to prevent light exposure. The tomatoes were subsequently washed with distilled water and drained just before homogenization. Tomatoes ripened under ambient temperature condition were picked at the breaker stages and ripened in the laboratory $\left(30 \pm 3{ }^{\circ} \mathrm{C}\right.$ ). Various tomatoes (about $500 \mathrm{~g}$ ) were chopped into about $1 \mathrm{~cm}$ cube pieces, blended and homogenized using an electric blender (Crownstar blender, Model No: MC-D299) for a set of analysis.

\section{Analysis of the total solid, $\mathrm{pH}$, titratable acidity and reducing sugar contents}

Determination of $\mathrm{pH}$ of tomatoes serum samples was carried out using a digital pH-meter (JENWAY 3520). The homogenized tomato sample was titrated against $0.01 \mathrm{M} \mathrm{NaOH}$ with phenolphthalein indicator to estimate the titratable acidity (which is calculated as \% citric acid) (AOAC, 2005). Total solid contents were analyzed by drying the tomato serum $(3 \mathrm{~g})$ in an oven, previously set at a temperature of $105^{\circ} \mathrm{C}$ for 3 hours (AOAC, 2005). The reducing sugar contents were quantified as previously described (Johnson et al., 1966). The tomato serum (1 ml) was mixed with $99 \mathrm{ml}$ of distilled water, which correspond to a dilution factor of $100.5 \%$ phenol solution $(1 \mathrm{ml})$ was added to $1 \mathrm{ml}$ of the aliquot earlier prepared followed by quick addition of $5 \mathrm{ml}$ of concentrated $\mathrm{H}_{2} \mathrm{SO}_{4}$. The solution was then allowed to cool and the absorbance was measured at $490 \mathrm{~nm}$ with the use of Genesys 10S V1.200 spectrophotometer (Buck Scientific, USA). Reducing sugar was then estimated from an already prepared calibration curve, using Beer-Lambert's law.

\section{Carotenoids extraction and quantification}

Extraction of lycopene and beta-carotene was done using solvent extraction method as reported earlier (Perkins-Veazie et al., 2001), with the use of the extraction solvent mixture containing methanol, hexane and acetone (1:2:1). Any triglyceride present in the extract was saponified by washing with a solvent mixture containing $20 \% \mathrm{KOH} /$ methanol, distilled water and methanol (1:1:1). This is followed by additional washing with distilled water while the upper hexane layer was kept. The absorbances of the hexane extracts were taken at 450 and $502 \mathrm{~nm}$ with the aid of a Genesys 10S V1.200 spectrophotometer (Buck Scientific, USA). Lycopene and $\beta$ carotene concentrations were then estimated simultaneously as previously reported (Abdul-Hammed et al., 2013; Fish, 2012).

\section{Data analysis}

The experimental determinations of each parameter were performed in triplicates and the mean values as well as standard deviations were obtained. The significant variations between these parameters were tested with respect to different ripening techniques and ripening stages using twoway Analysis of Variance (ANOVA) at $\alpha=0.05$ level of significance. The statistical analysis was performed on OriginPro 8 software (OriginLab Corp., Northampton, MA).

\subsection{Results and Discussion}

\section{pH variation in tomato cultivars}

The $\mathrm{pH}$ values of the five tomato cultivars vary with the degree of ripeness as well as the ripening techniques (Figure 1). The $\mathrm{pH}$ values of tomatoes 
ranged from 3.58 to 3.98 and 3.80 to 4.07 for semi-ripe and fully-ripe tomatoes, respectively, under field ripening condition as compared to 3.46 to 5.40 and 3.72 to 5.35 respective ranges observed under ambient temperature ripening condition. This is in agreement with previously reported trend (Abdul-Hammed et al., 2009). The variation of the mean $\mathrm{pH}$ values of the tomatoes ripened under field ripening were insignificant $(\mathrm{p}>$ $0.05)$ within the cultivars, however significant differences $(\mathrm{p}<0.05)$ exist between the mean $\mathrm{pH}$ values of semi-ripe and fully-ripe tomatoes under the same condition. Under ambient temperature ripening techniques, the mean $\mathrm{pH}$ values obtained were significantly different $(\mathrm{p}<0.05)$ with respect to both the ripening stages and cultivars. The desired $\mathrm{pH}$ of below 4.5 is a desirable trait since tomato products are classified as acidic foods and the growth of harmful microorganisms in the processed products is inhibited under acidic conditions (da Silva et al., 2008). The low $\mathrm{pH}$ values obtained at all ripening stages indicate high acidity which correlates well with total fruit flavour (Kader, 1978). Therefore it is likely that the tomatoes ripened under ambient temperature ripening condition would be less sweet than those ripened under field ripening condition, as good correlation between high acidity (low $\mathrm{pH}$ ) and sweetness has been previously established (Doris et al., 2001).

\section{Tomato titratable acidity}

The three major components of fleshy fruits are $\mathrm{pH}$, titratable acidity and reducing sugar contents and they all, together with sugars and volatile flavour compounds, contribute to the sourness and sweetness indices of the fruits (Abdul-Hammed et al., 2012; Cohen et al., 2014). Different ripening techniques and degree of ripening influence tomatoes titratable acidity as shown in Figure 2. Under field ripening technique, the titratable acidity values range from 0.24 to $0.38 \%$ and 0.18 to $0.32 \%$ for semi-ripe and fully-ripe tomatoes, respectively, while the values ranging from 0.15 to $0.25 \%$ and 0.15 to $0.33 \%$ were observed for semi-ripe and fully-ripe tomatoes under ambient temperature ripening conditions, respectively. It was observed that the semi-ripe tomatoes have slightly higher acidity than full-ripe tomatoes under field ripening technique whereas, the fully-ripe tomatoes were observed to have higher acidity under ambient temperature ripening condition. The differences in the mean titratable acidity values between the two ripening stages and among the cultivars were statistically significant $(\mathrm{p}<0.05)$.

\section{Total Solid contents}

The total solid content is an important parameter which contributes to the economic importance of tomato in tomato processing industries as well as the desirable longer shelf life of the fruits (Abdul-Hammed et al., 2012). As shown in Figure 3, the total solid contents of the tomatoes ranged from 5.61 to $7.21 \%$ and 6.54 to $8.31 \%$ in fully-ripe and semi-ripe tomatoes under field ripening condition, respectively, while the ranges under ambient temperature technique were 4.09 to $7.16 \%$ and 5.12 to $7.00 \%$, respectively. Of all the cultivars, Ogbomoso local cultivar has the highest total solid content $(8.31 \%)$ which was obtained at the semi-ripe stage of the field ripening technique, while the lowest value (4.09\%) was obtained in fully-ripe San Marz tomatoes under ambient temperature ripening condition. This agrees well with another report which showed that the total solid contents of cultivated tomatoes range between 4.5 and $8.5 \%$ of its fresh weight (Javanmardi and Kubota, 2006). The total solid contents of the tomatoes were statistically significant $(\mathrm{p}<0.05)$ with respect to the cultivars as well as the degrees and stages of tomato ripeness.

\section{Reducing Sugar contents}

The reducing sugar contents of the tomato cultivars under study were shown in Figure 4. For field ripening technique, the least and highest reducing sugar contents $(1.84$ and $5.12 \mu \mathrm{g} / \mathrm{g})$ were obtained in semi-ripe Nasmata and fully-ripe Ogbomoso-local tomatoes, respectively, while the least and highest values ( 2.33 and $5.23 \mu \mathrm{g} / \mathrm{g}$ ) were observed for semi-ripe Nasmata and Ogbomoso-local tomatoes under ambient temperature ripening condition, respectively. Significant differences $(p<0.05)$ exist in the reducing sugar contents between the cultivars as well as the degrees and stages of tomato ripeness. This claim is also in line with experimental results in previous reports (Ibrahim et al., 2017; Kaur et al., 2006). Sugar and organic acid contents of a particular tomato fruit is greatly dependent on the ripening stages. As reported previously, tomato ripens in different stages with the total sugar content increasing to approximately $4 \%$. Glucose predominates at the unripe stage, whereas fructose dominates at fully-ripe stage (Anthon et al., 2011; Davies and Kempton, 1975; Yelle et al., 1988). Conversely, as tomatoes continue to mature after ripening, the sugar contents reportedly declined (Anthon et al., 2011).

\section{Lycopene contents in tomato cultivars}

Lycopene is a carotenoid that has been reported to be a strong antioxidant and its consumption has been linked to the prevention of cancers, such as prostate cancer, and as a strong protective agent against neurodegenerative diseases (Rao et al., 1998). The variation of the lycopene contents of the tomatoes under study with different stages and techniques of ripening is shown in Figure 5. The lycopene contents ranged from 0.47 to $17.18 \mu \mathrm{g} / \mathrm{g}$ and 0.64 to $7.75 \mu \mathrm{g} / \mathrm{g}$ for the field and ambient temperature ripening techniques. Under field ripening condition, fully-ripe Roma VF tomatoes have the highest lycopene content $(17.18 \mu \mathrm{g} / \mathrm{g})$ while lower values were observed in semi ripe tomatoes with the lowest value $(0.47 \mu \mathrm{g} / \mathrm{g})$ obtained in semi-ripe 4-lobes tomatoes. The lycopene contents are generally lower in tomatoes ripened under ambient temperature condition and a further decreasing trend was also observed from fully-ripe to semi-ripe tomatoes with the highest $(7.75 \mu \mathrm{g} / \mathrm{g})$ and lowest $(0.64 \mu \mathrm{g} / \mathrm{g})$ in fully-ripe Roma VF tomatoes and semi-ripe San Marz tomatoes. These values fall within the reported range of tomatoes lycopene contents (Raffo et al., 2002). The differences in the mean lycopene contents between the two ripening stages and among the cultivars were statistically significant $(\mathrm{p}<0.05)$. Reports showed that more than $80 \%$ of the total lycopene dietary intake are from fresh tomato and its commercial products, when consumed in large quantity (Amiri-Rigi and Abbasi, 2016). Our observation also supported the assertion that fully-ripe tomatoes that are ripened under field condition are better sources of lycopene when compared to those subjected to ambient temperature ripening technique, as observed in other local tomato cultivars (Abdul-Hammed et al., 2012).

\section{Beta-carotene contents}

Beta-carotene content (pro-vitamin A index) of the tomato cultivars vary with degree and technique of ripeness (Figure 6). Under field ripening condition, beta-carotene contents ranged from 0.78 to $2.47 \mu \mathrm{g} / \mathrm{g}$ and 4.09 to $5.64 \mu \mathrm{g} / \mathrm{g}$ for semi-ripe and fully ripe stages, respectively, while lower values which range from 0.59 to $0.85 \mu \mathrm{g} / \mathrm{g}$ and 1.17 to $2.80 \mu \mathrm{g} / \mathrm{g}$ were observed for semi-ripe and fully ripe stages, respectively, under ambient temperature ripening condition. These values are within the same range in previous reports on some tomato cultivars (Baranska et al., 2006; Garande and Patil, 2014). The trend in the variation of beta-carotene contents was similar to those observed for lycopene contents, and higher beta-carotene contents were also observed in fully-ripe tomatoes. However, it was noted 
that the $\beta$-carotene contents of the tomato cultivars under the field ripening technique are significantly higher $(p<0.05)$ than those obtained under ambient temperature ripening technique. Although beta-carotene is present in many foods, it is also taken orally as a dietary supplement. It contributes significantly to the orange color of several fruits and vegetable crops such as mangoes, papayas, carrots, tomatoes and sweet potatoes, among others (Kidmose et al., 2005). Beta-carotene has been identified as a singlet oxygen quencher and an immune modulator thereby helping to reduce the incidences of cancer, and is also reported to be protective against DNA damage due to its antioxidant activity. (Wang and Russell, 1999), Dietary beta-carotene are recommended by medical authorities rather than carotenoid supplements, and a minimum level of beta-carotene consumption important for human health is yet to be determined, and the controversy regarding the beta-carotene supplements intake continues (Patrick, 2000), although strict vegetarians depend on beta-carotene as their main source of vitamin A daily requirements.
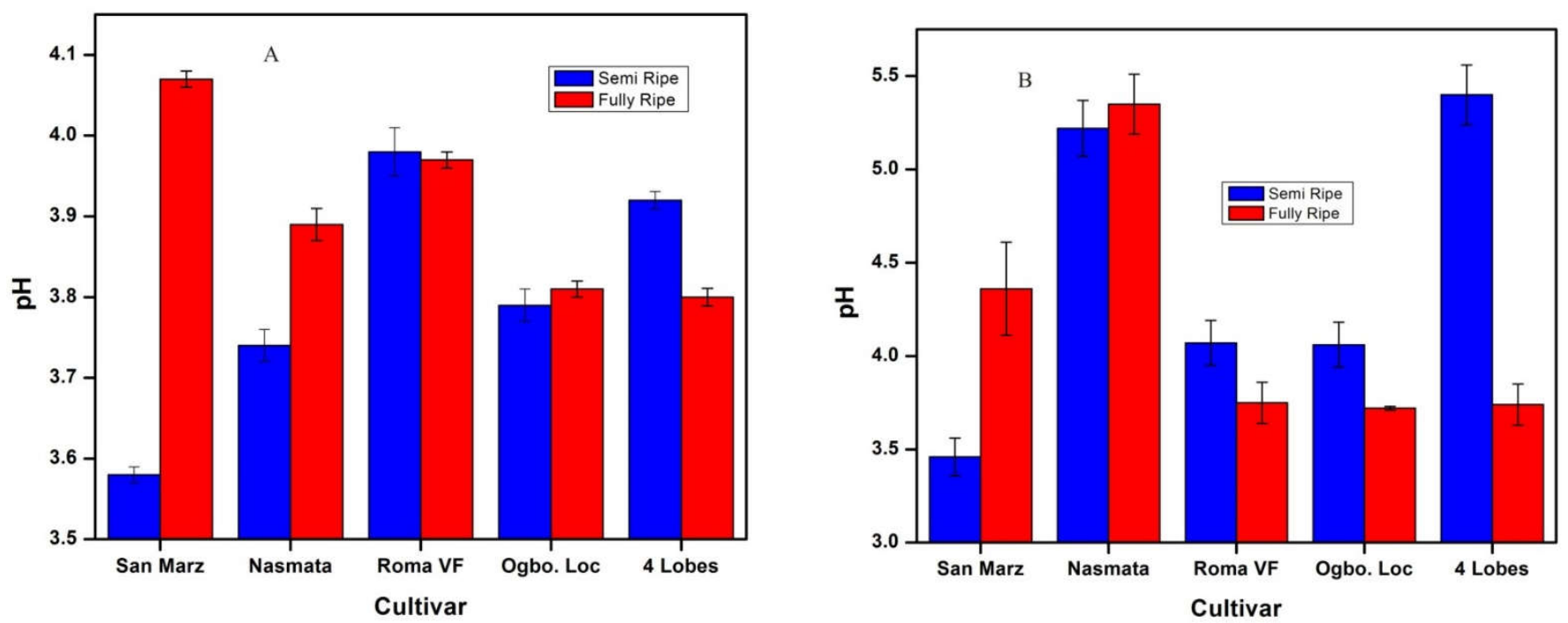

Figure 1: Variation in $\mathrm{pH}$ of fully and semi ripe tomatoes of five cultivars under (A) field and (B) ambient temperature ripening. Mean values and standard deviations are reported for triplicate analysis. The differences between the mean values were significant at $\mathrm{p}<0.05$.
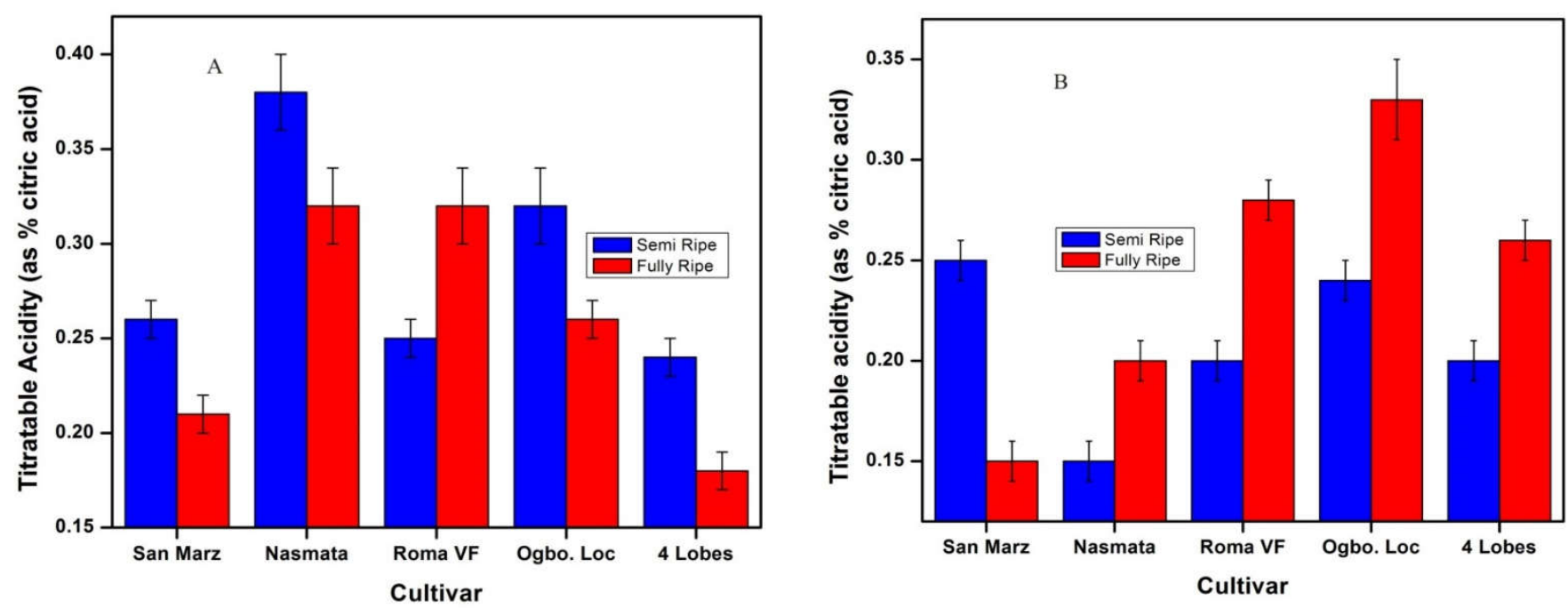

Figure 2: Variation in titratable acidity (measured as \% citric acid) of fully and semi ripe tomatoes of five cultivars under (A) field and (B) ambient temperature ripening. Mean values and standard deviations are reported for triplicate analysis. The differences between the mean values were significant at $\mathrm{p}<0.05$. 

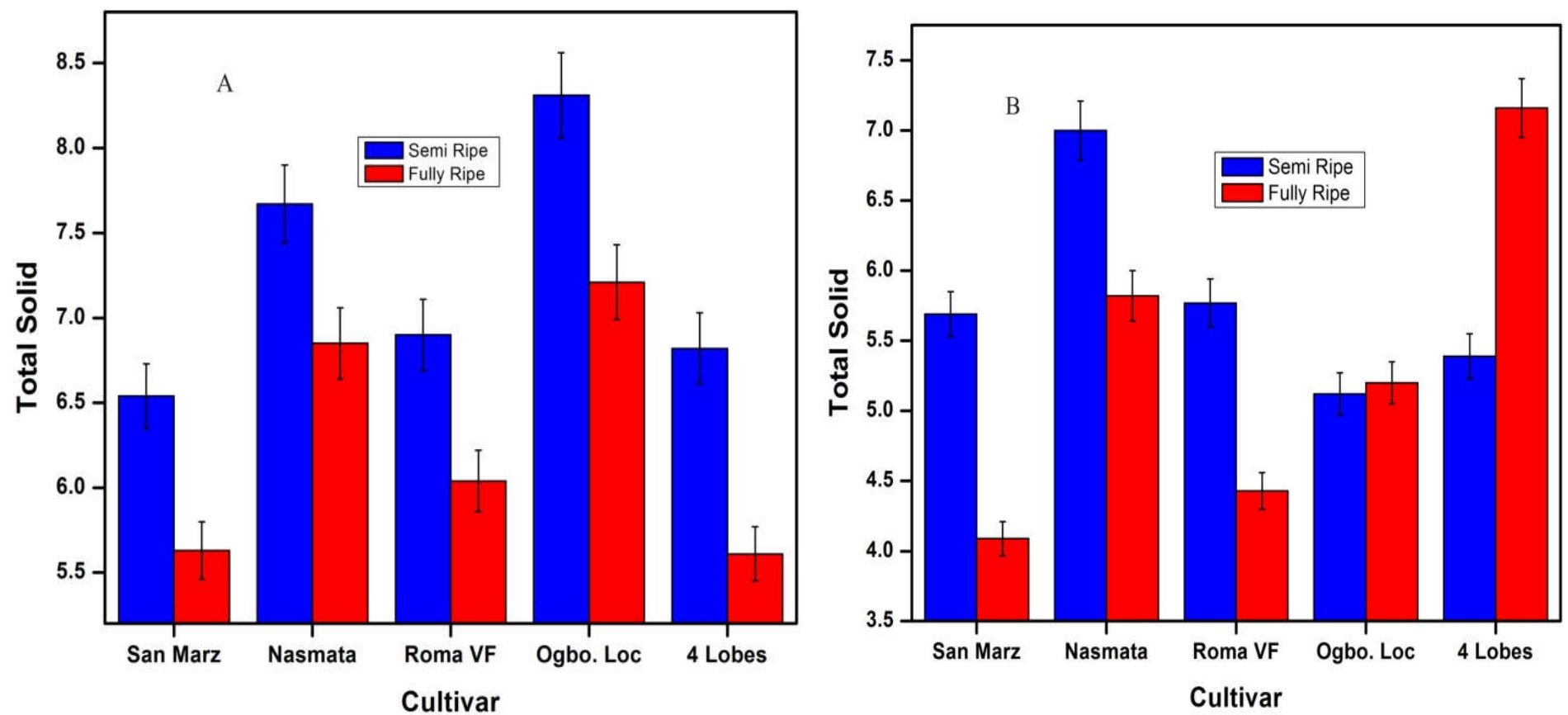

Figure 3: Variation in total solid (\%) contents of fully and semi ripe tomatoes of five cultivars under (A) field and (B) ambient temperature ripening. Mean values and standard deviations are reported for triplicate analysis. The differences between the mean values were significant at $\mathrm{p}<0.05$.
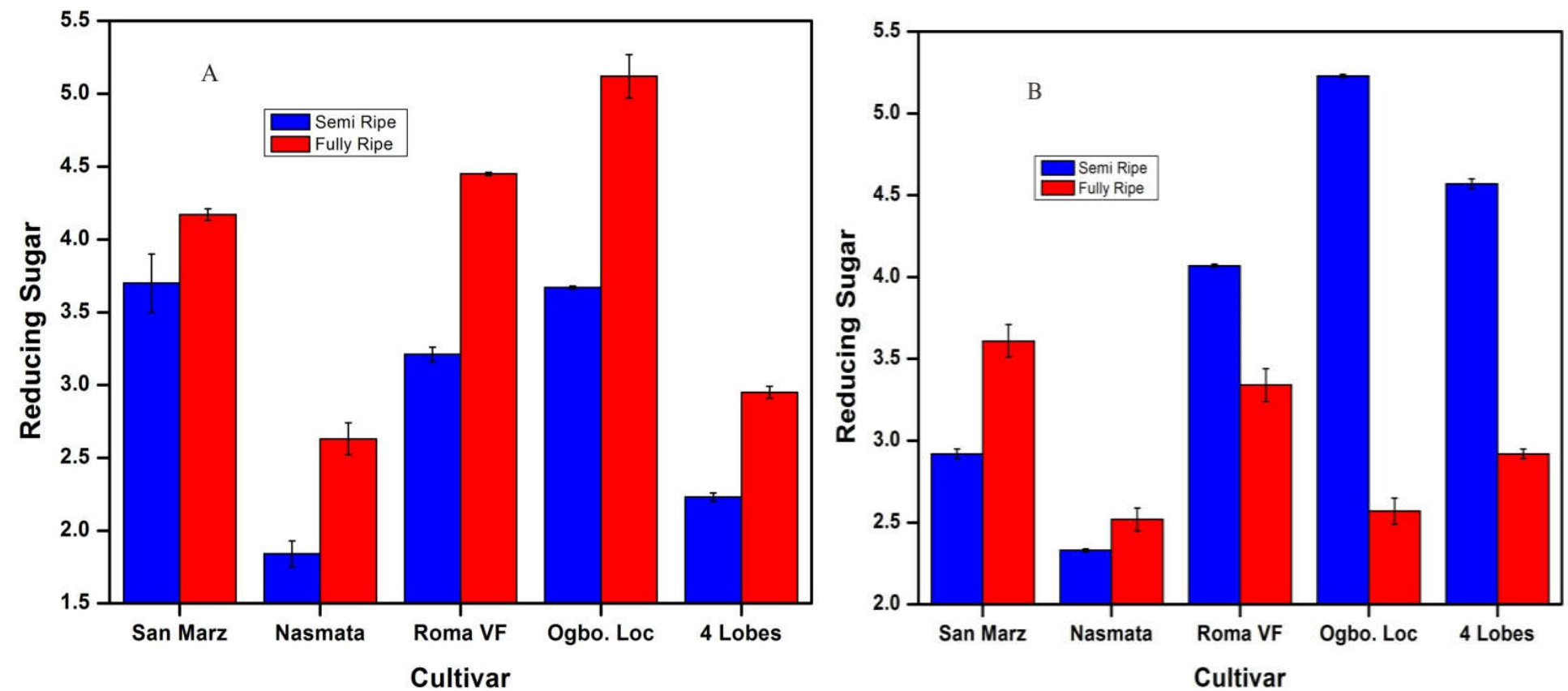

Figure 4: Variation in the reducing sugar contents $(\mu \mathrm{g} / \mathrm{g})$ of fully and semi ripe tomatoes of five cultivars under (A) field and (B) ambient temperature ripening. Mean values and standard deviations are reported for triplicate analysis. The differences between the mean values were significant at $\mathrm{p}<0.05$. 

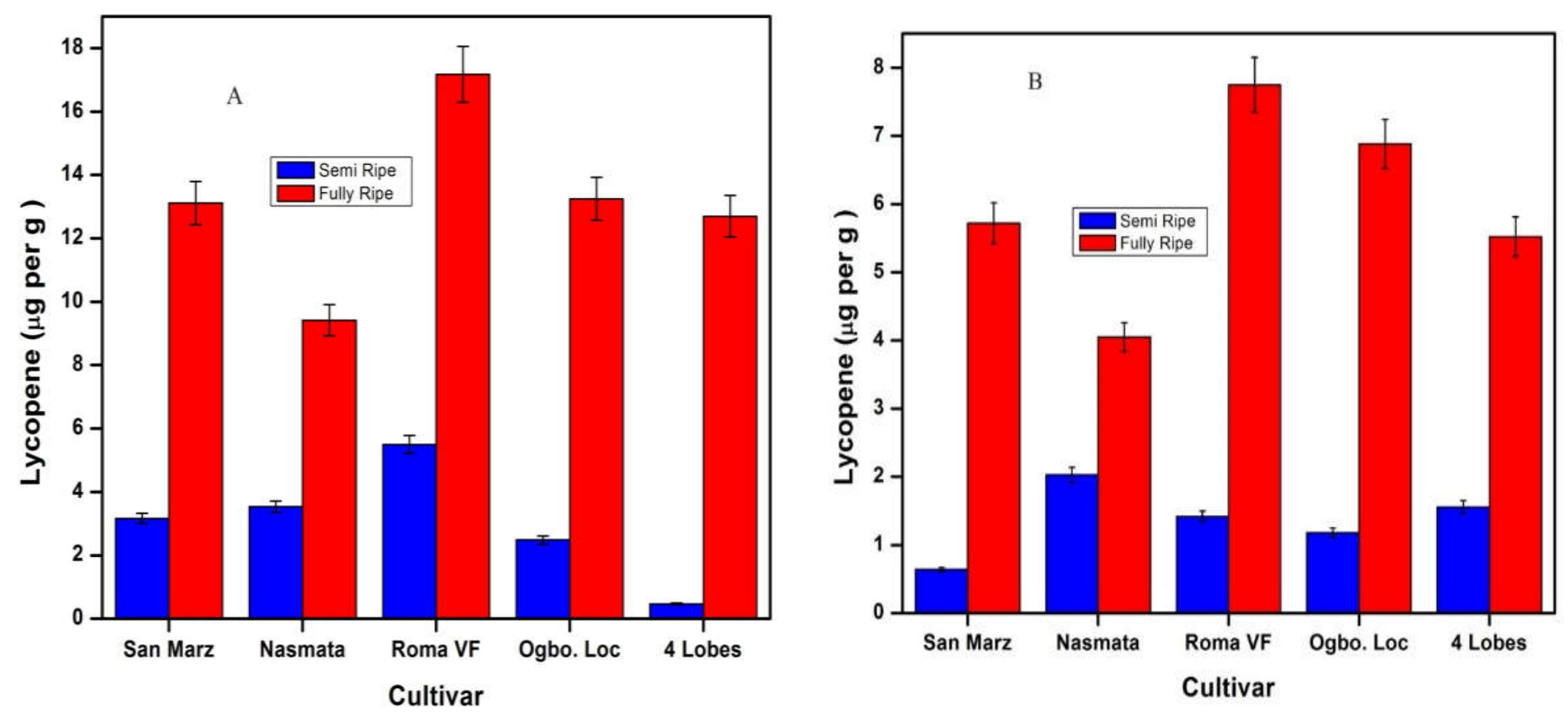

Figure 5: Variation in the lycopene contents of fully and semi ripe tomatoes of five cultivars under (A) field and (B) ambient temperature ripening. Mean values and standard deviations are reported for triplicate analysis. The differences between the mean values were significant at $\mathrm{p}<0.05$.
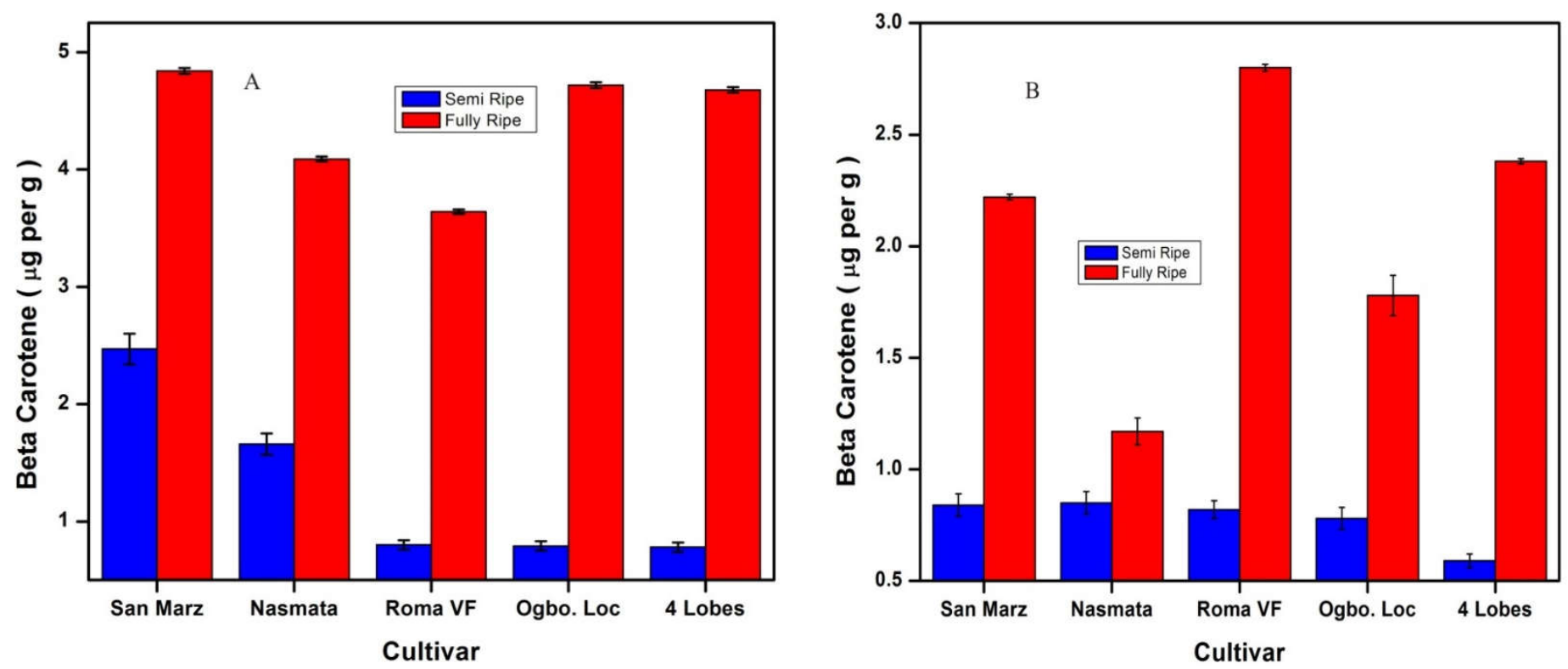

Figure 6: Variation in the beta-carotene contents of fully and semi ripe tomatoes of five cultivars under (A) field and (B) ambient temperature ripening. Mean values and standard deviations are reported for triplicate analysis. The differences between the mean values were significant at $\mathrm{p}<0.05$. 


\subsection{Conclusion}

The $\mathrm{pH}$, titratable acidity and reducing sugar of five cultivars of tomato under study revealed that variations exist in these parameters depending on the cultivar, degree of ripening and the ripening technique employed. Consumption of tomatoes for the purpose of sweetness is encouraged at a semi-ripe stage while for economic and industrial processing, field ripened (fully-ripe) tomatoes could be of more importance, the high $\mathrm{pH}$ values obtained at ambient temperature ripening conditions are undesirable. Commonly available cultivar (Ogbomoso-Local) in the locality of the environment in which the experiment was carried out (Ogbomoso town, Oyo state, Nigeria) is more desirable at semi-ripe and fully-ripe stages under field ripened technique. Consumption of tomatoes for the purpose of dietary antioxidant lycopene and pro vitamin A index of tomatoes $(\beta$ carotene) is encouraged at fully-ripe stage under field ripening condition. Hence, cultivation, harvest and postharvest handling of tomatoes should be given proper attention in our agricultural practices while consumption of tomatoes and its products should be included as a major part of our diets due to its enormous dietary and economic importance.

\section{Conflict of Interest}

The authors declare no conflict of interest.

\section{Acknowledgement}

The authors hereby acknowledge the Senate grant support (LAU/SRG/13/010) provided by the Research and Consultancy unit of LAUTECH, Ogbomoso. We also thank Prof. A.T.J. Ogunkunle of LAUTECH Herbarium, Ogbomoso for the identification of the tomatoes.

\section{Authors Contribution \\ Conception: [MA-H] \\ Design: [MA-H and $\mathrm{OAI}]$ \\ Execution: [SAA and MO] \\ Interpretation: [MA-H, MO and SAA] \\ Writing of the paper: [MA-H, SAA and AAA].}

\section{References}

Abdul-Hammed, M., Bello, I.A., Oladoye, S.O., 2013, Simultaneous spectrophotometric determination of lycopene and beta-carotene concentrations in carotenoid mixtures of the extract of tomatoes, papaya and orange juice. Pakistan Journal of Scientific and Industrial Research Series B: Biological Sciences, 56 (2): 90-97.

Abdul-Hammed, M., Bello, I.A., Olajire, A.A., 2009, Comparison of biochemical and physiological properties of Nigerian tomato fruits ripened under different conditions. African Journal of Food, Agriculture, Nutrition and Development, 9 (9): 1859-1877.

Abdul-Hammed, M., Ibrahim, A.O., Kosoko, A.R., 2012, Impact of ripening techniques on the biochemical and physiological changes in tomatoes (3-Lobes and Big-Local cultivars). Australian Journal of Basic and Applied Sciences, 6 (9): 17-24.

Abdulnabi, A.A., Emhemed, A.H., Hussein, G.D., Peter, A.B., 1997, Determination of antioxidant vitamins in tomatoes. Food Chemistry, 60 (2): 207-212.

Amiri-Rigi, A., Abbasi, S., 2016, Microemulsion-based lycopene extraction: Effect of surfactants, co-surfactants and pretreatments. Food Chemistry, 197 (Part A): 1002-1007.
Ansari, M.S., Gupta, N.P., 2004, Lycopene: a novel drug therapy in hormone refractory metastatic prostate cancer. Urologic Oncology: Seminars and Original Investigations, 22 (5): 415-420.

Anthon, G.E., LeStrange, M., Barrett, D.M., 2011, Changes in pH, acids, sugars and other quality parameters during extended vine holding of ripe processing tomatoes. Journal of the Science of Food and Agriculture, 91 (7): 1175-1181.

Association of Official Analytical Chemists, AOAC, 2005, Official Methods of Analysis. 18th Ed. Arlington, Virginia: Association of Official Analytical Chemists.

Baranska, M., Schu, W., Schulz, H., 2006, Determination of lycopene and $\beta$-carotene content in tomato fruits and related products: Comparison of FT-Raman, ATR-IR, and NIR Spectroscopy. Analytical Chemistry, 78 (24): 8456-8461

Burton-Freeman, B., Reimers, K.J., 2011, Tomato consumption and health: Emerging benefits. American Journal of Lifestyle Medicine, 5 (2): 182-191.

Cohen, S., Itkin, M., Yeselson, Y., Tzuri, G., Portnoy, V., Harel-Baja, R., Lev, S., Sa'ar, U., Davidovitz-Rikanati, R., Baranes, N., Bar, E., Wolf, D., Petreikov, M., Shen, S., Ben-Dor, S., Rogachev, I., Aharoni, A., Ast, I., Schuldiner, M. et al., 2014, The PH gene determines fruit acidity and contributes to the evolution of sweet melons. Nature Communications, 5: 4026.

da Silva, D.J.H., Abreu, F.B., Caliman, F.R.B., Antonio, A.C., Patel, V.B., 2008, In V.R. Preedy, \& Watson, R.R. (Eds). Tomatoes and tomato products - Nutritional, medicinal and therapeutic properties: Tomatoes - Origin, Cultivation Techniques and Germplasm Resources (1st ed, pp. 3-25). New Hampshire: Science Publishers, 643p.

Davies, J.N., Kempton, R.J., 1975, Changes in the individual sugars of tomato fruit during ripening. Journal of the Science of Food and Agriculture, 26: 1103-1110.

Devasagayam, T.P.A., Wener, T., Ippendorf, H., Martin, H.D., Sies, H., 1992, Synthetic carotenoids, novel polyene, polyketones and new absorbing isomers as efficient quencher of singlet molecular oxygen. Photochemistry and Photobiology, 55 (4): 511-514.

Doris, M., Gosselin, A., Papadopoulos, A.P., 2001, In J. Janick editor, Horticultural Reviews: Greenhouse Tomato Fruit Quality (Volume 26, pp 239-319). Hoboken, New Jersey: Wiley, 368p.

Fawole, A., Opara, U.L., Theron, K.I., 2012, Chemical and phytochemcial properties and antioxidant activities of pomegranate cultivars grown in South Africa. Food and Bioprocess Technology, 5 (7): 2934-2940.

Fish, W.W., 2012, Refinements of the attending equations for several spectral methods that provide improved quantification of $\beta$-carotene and/or lycopene in selected foods. Postharvest Biology and Technology, 66, 16-22.

Garande, V.K., Patil, R.S., 2014, Orange fruited tomato cultivars : Rich source of beta-carotene. Journal of Horticulture, 1 (2): 1000108

Ibrahim, M., Helali, M.O.H., Alam, A.K.M.S., Talukder, D., Akhter, S., 2017, Physiological and biochemical characteristics of different tomato grown in Rajshahi region of Bangladesh. Bangladesh Journal of Scientific and Industrial Research, 52 (3): 195-200. 
Javanmardi, J., Kubota, C., 2006, Variation of lycopene, antioxidant activity, total soluble solids and weight loss of tomato during postharvest storage. Postharvest Biology and Technology, 41 (2): 151155.

Johnson, R.R., Balwani, T.L., Johnson, L.J., Mcclure, K.E., Dehority, B.A., 1966 , Corn plant maturity. II. Effect on in vitro cellulose digestibility and soluble carbohydrate content. Journal of Animal Science, 25 (3): 612-623.

Kader, A.A., 1978, Influence of pre-harvest and postharvest environment on nutritional composition of fruits and vegetables. In: Proceeding of the 1st International Symposium of Horticulture \& Human Health. ASHS Symposium Series. pp. 18-32.

Kahlaoui, B., Hachicha, M., Misle, E., Fidalgo, F., Teixeira, J., 2018, Physiological and biochemical responses to the exogenous application of proline of tomato plants irrigated with saline water. Journal of the Saudi Society of Agricultural Sciences, 17 (1): 17-23.

Kaur, D., Sharma, R., Wani, A.A., Singh, B., Sogi, D.S., 2006, Physicochemical changes in seven tomato (Lycopersicon esculentum) cultivars during ripening. International Journal of Food Properties, 9 (4): 747-751.

Kidmose, U., Edelenbos, M., Christensen, L.P., Hegelund, E., 2005, Chromatographic determination of changes in pigments in spinach (Spinacia oleracea L.) during processing. Journal of Chromatographic Science, 43 (9): 466-472.

Opara, U.L., Al-Ani, M., 2010, Antioxidant contents of prepacked freshcut versus whole fruit and vegetables. British Food Journal, 112 (8): 797-810.

Patrick, L., 2000, Beta-carotene: the controversy continues. Alternative Medicine Review, 5 (6): 530-545.

Perkins-Veazie, P., Collins, J.K., Pair, S.D., Roberts, W., 2001, Lycopene content differs among red-fleshed watermelon cultivars. Journal of the Science of Food and Agriculture, 81 (10): 983-987.

Raffo, A., Leonardi, C., Fogliano, V., Ambrosino, P., Salucci, M., Gennaro, L., Bugianesi, R., Giuffrida, F., Quaglia, G.J., 2002, Nutritional value of cherry tomatoes (Lycopersicon esculentum $\mathrm{Cv}$. Naomi F1) harvested at different ripening stages. Journal of Agricultural and Food Chemistry, 50 (22): 6550 -6556.

Raiola, A., Rigano, M.M., Calafiore, R., Frusciante, L., Barone, A., 2014, Enhancing the health-promoting effects of tomato fruit for biofortified food. Mediators of Inflammation, 2014; ID 139873 (1-16).

Rao, A.V., Zeeshan, W., Sanjiv, A., 1998, Lycopene content of tomatoes and tomato products and their contribution to dietary lycopene. Food Research International, 31 (10): 737-741.

Shankara, N., Joep, VanLidt, J., Marjade, G., Martin, H., Barbara, V., 2005, Cultivation production, processing and marketing of tomato. Wageningen, The Netherlands: Agromisa Foundation, 92p.

Slimestad, R., Verheul, M., 2009, Review of flavonoids and other phenolics from fruits of different tomato (Lycopersicon esculentum Mill) cultivars. Journal of the Science of Food and Agriculture, 89 (8): $1255-1270$

Stahl, W., Sies, H.. 2003, Antioxidant activity of carotenoids. Molecular Aspects of Medicine, 24 (6): 345-351.
Suárez, M.H., Rodríguez-Rodríguez, E.M., Romero, C.D., 2008, Chemical composition of tomato (Lycopersicon esculentum) from Tenerife, the Canary Islands. Food Chemistry, 106 (3): 1046-1056.

Wang, X.D., Russell, R.M., 1999, Procarcinogenic and anticarcinogenic effects of beta-carotene, Nutrition Reviews, 57 (9): 263-272.

Yelle, S., Hewitt, J.D., Robinson, N.L., Damon, S., Bennett, A.B., 1988, Sink metabolism in tomato fruit: III. Analysis of carbohydrate assimilation in a wild species, Plant Physiology, 87 (3): 737-740. 